\title{
Do People Become Healthier after Being Promoted?
}

\author{
Christopher J. Boyce \\ Department of Psychology, University of Warwick, UK \\ Email: c.j.boyce@warwick.ac.uk \\ Andrew J. Oswald \\ Department of Economics, University of Warwick, UK \\ Email: andrew.oswald@warwick.ac.uk
}

16 December 2008

\begin{abstract}
This paper uses longitudinal data to explore whether greater job status makes a person healthier. Taking the evidence as a whole, promotees do not exhibit a health improvement after promotion. Instead the data suggest that workers with good health are more likely to be promoted. In the private sector, we find that job promotion significantly worsens people's psychological strain (on a GHQ score). For the public sector, there are some tentative signs of the reverse. We discuss caveats to our conclusions, suggest caution in their interpretation, and argue that further longitudinal studies are needed.
\end{abstract}

Keywords: Health; Whitehall studies; GHQ; locus of control; job satisfaction; mortality; status

JEL codes: I1

Corresponding author: c.j.boyce@warwick.ac.uk

Address: Department of Psychology, University of Warwick, Coventry CV4 7AL.

Telephone: (+44) 02476523158

Acknowledgements: For helpful discussions and advice, we thank Mel Bartley, David Blane, George

Davey-Smith, Jane Ferrie, Hugh Gravelle, Andrew Steptoe and Richard Wilkinson. We have also benefited from valuable comments in seminars in both the economics and psychology departments at Warwick University and the work-psychology research group at Sheffield University. The Economic and Social Research Council (ESRC) provided research support. The British Household Panel Survey data were made available through the UK Data Archive. The data were originally collected by the ESRC Research Centre on Micro-social Change at the University of Essex, now incorporated within the Institute for Social and Economic Research. Neither the original collectors of the data nor the Archive bears any responsibility for the analyses or interpretations presented here. 


\section{Do People Become Healthier after Being Promoted?}

\section{Introduction}

Individuals of high occupational status have good health and low rates of premature mortality. The difficulty for the statistical investigator is to know how to interpret this cross-section association. Is it causal?

In this paper we attempt to implement a longitudinal test of the hypothesis that improvements in occupational status lead to better health. The focus is on individuals' job rank, and thus approximately their degree of control, within the workplace. We draw upon a panel data set, collected annually between 1991 and 2005, with information on approximately 1000 individual promotions. We follow what happens to the health of those who gain seniority when compared to the health of those who do not. With one exception, this paper does not find evidence in favour of a status-causes-health theory. Those who are promoted are significantly healthier before their promotion, and job promotion in many instances apparently brings about a worsening of mental health. However, after being promoted to the position of manager, people do go on to reduce by approximately $10 \%$ the number of times they visit their doctor.

Early cross-sectional evidence emerged from a study of the British civil service (Bosma et al. 1997; Marmot et al. 1978; Marmot, Shipley and Rose 1984; Marmot et al. 1991). In interesting and influential work, researchers such as Marmot (2004) and Wilkinson (2001) have argued that there is a cause-and-effect connection running from status to health. According to this account, high status may itself boost health. It is argued that feelings of inadequacy, anxiety and ultimately a lack of life control can arise from low job and social status. Such psychosocial stressors are detrimental to the human condition, especially to cardiovascular health and the auto- 
immune system, and they can explain much of the social health gradient (Marmot et al. 1997). Griffin et al. (2002) and others have argued that greater control at work also improves mental health.

Evidence for causation from health to status comes principally from crosssections. The existence of a positive association between health and occupation, the so-called health gradient, is undisputed (Johnson, Sorlie and Backlund 1999; Macleod et al. 2005; Marmot, Shipley and Rose 1984). Nevertheless, for reasons of data availability, there has remained a shortage of longitudinal analysis. Untangling the relationship between human health and socio-economic status is also a complicated task. Whilst there may be a causal chain running from status to health, it may also operate in the opposite direction, with the healthiest individuals going on to obtain the higher status (Deaton 2003; Smith 1999; West 1991). Alternatively, a third unobservable influence, such as genetic factors, could cause both good health and job success (Adams et al. 2003; Cutler, Deaton and Lleras-Muney 2006).

Using various SES indicators, attempts have been made to address the problem of causality. For example, Adams et al (2003) for the US and Adda, Chandola and Marmot (2003) for Sweden and the UK use longitudinal data and control for initial health. No clear causal effects from SES to health are found. Similarly, Gardner and Oswald (2004) control for initial health at $\mathrm{T}$ in an annual panel on individuals and find that income does not influence survival probability at $\mathrm{T}+10$. Whilst they adjust for pre-existing health conditions, these studies cannot discount the possibility that individuals' early health led to their SES. Using instrumental variables, however, Ettner (1996) argues that more income appears to result in significantly better physical and mental health. Lorgelly and Lindley (2008) also find, using fixed effects regressions, that although absolute income influences health, there 
are no independent effects of either relative income or income inequality. Wilkinson (1986) examines the link between changes to both occupational mortality and occupational incomes over a twenty year period; however, the units of observation in his study are occupations rather than data on individuals.

The fact that researchers can manipulate the social hierarchy of animals makes the research on rank's effect on animal health of interest. Sapolsky (2004) experimentally documents that health consequences emerge relatively quickly after rank is established across groups of animals, including monkeys. Sapolsky (2004) further suggests that this pattern extends to humans. However, the social context differs across species. For example, subordinate animals that embark in cooperative breeding (Abbott et al. 1998) generally do not suffer from elevated release of glucocorticoids, a classic negative stress response documented in Sapolsky, Romero and Munck (2000). Similarly, this stress response within species is dependent on whether the subordinate animals are subjected to high levels of harassment by dominant individuals and whether they have social support networks (Abbott et al. 2003).

Exogenous manipulation of a human individual's status is not possible, but near-experiments potentially provide a way in which one might try to uncover causal effects. Rablen and Oswald (2008) offer support for a causal effect, running from social status to health, in the upper echelons of society. They demonstrate that Nobel Prize winners live approximately one to two years longer than those merely nominated for the Prize. Their results are similar to, though use more controls and different statistical methods than, that of an analysis of Academy Award winners carried out by Redelmeier and Singh (2001). Although both studies are suggestive, an inference of causality needs the strong assumption that winners and near-winners are 
randomly assigned with respect to their status. Snyder and Evans (2006) focus on a quasi-experiment in the realm of income. They find, counter-intuitively, that those with higher incomes as a result of changes to social security payments also have greater mortality rates. This result is somewhat consistent with findings by Ruhm (2000) that temporary upturns in the economy are bad for people's health.

One version of the causality argument suggests that access to resources in the form of income plays only a small part in explaining health differences (Marmot 2004; Wilkinson 2001). Nevertheless, the correlation between health and income is strong (recent econometric evidence includes Cantarero and Pascual (2005), Duleep (1986), Frijters, Haisken-DeNew and Shileds (2005), McDonough et al. (1997), Menchik (1993) and Wolfson et al. (1993)) and similarly so for education (Feldman et al. 1989; Lahelma and Valkonen 1990). Income, education and occupation all give fairly good indications of an individual's socio-economic status (SES). Duncan et al (2002) argue that economic measures, such as pay, are preferable over the traditional measures of SES. Yet income will correlate well with psychosocial aspects and therefore with health. It is important to isolate independent SES effects, although exclusion of correlated variables will bias the estimates (Fuchs 2004).

The work environment offers a useful background to uncover possible psychosocial aspects of status while allowing other SES indicators, such as income and education, to be held constant. Consistent with this line of thinking, Ala-Mursula et al (2005) conclude that women with less work-time control have an increased risk of health problems. Fischer and Sousa-Poza (2009) conclude that an increase in job satisfaction improves an individual's health. Anderson and Marmot (2007) exploit differences in promotion rates across departments in the British civil service as an instrument for individual promotion. 


\section{Methodology}

Our analysis focuses on one-time improvements in an individual's occupational status. The methodological idea is a straightforward one. Consider an individual who is promoted at time $\mathrm{T}$. If causality runs solely from occupational status to health, then, after controlling for other factors correlated with health and promotion (such as age, education and gender), there should be no significant differences, at $\mathrm{T}-1$, in the health of those who are promoted and those who are not promoted. At $\mathrm{T}+1$ there should begin to be a difference. If there is only reverse causality -- that is, causality running from health to occupational status -- then promoted individuals should exhibit significantly better health to the same degree at both $\mathrm{T}-1$ and after $\mathrm{T}+1$. Were two-way causality to exist, a promoted group would exhibit a combination of these two effects. Not only would they have better health at T-1, but their health would continue to improve compared with that of the notpromoted group.

Using longitudinal data, on a large sample of British workers, cross-sectional and difference-in-difference methods are used here to explore each of these three hypotheses. It is useful to note that the data set has no identifiers for employers or firms. Our promoted group therefore includes those who improve their occupational status internally and those who gain extra seniority after a move to a different employer.

\section{Data and Estimation Issues}

Seniority and job status come in myriad forms. An empirical inquiry has to make some taxonomic assumption. In this study, an individual's role in the 
workplace is assumed to be captured by whether they report in the British Household Panel Survey that

: their job is one of... manager, supervisor, or neither of these.

In the data set, these are uniquely different classifications ${ }^{1}$, which are similar to those used by Macleod et al. (2005). While this approach necessarily aggregates across sectors in a way that may produce some measurement error, it offers an indication of the seniority and hence the degree of control each individual can be expected to have in the job. This taxonomy of seniority assumes away complex role overlaps, and assumes too that an individual is employed, which means that any association between unemployment and poor health will be largely ignored in our main analysis. We return later to this issue.

Data come from the British Household Panel Survey (BHPS), a representative longitudinal sample of British households. Running from 1991-2005, the Survey tracks over 10,000 adults in each of 15 years. Our analysis concentrates on a particular proportion of this sample, namely, those who worked for at least five consecutive years, from, in our notation, $\mathrm{T}-1$ up to $\mathrm{T}+3$. We observe who is promoted at $\mathrm{T}^{2}$. This gives us a sample size of up to approximately 17,000 individual five-year observations.

There is some loss to this research design, because we are unable to say whether those who left work entirely, or subsequently changed role again, went on as a result to have better or worse health ${ }^{3}$. But it allows a simple focus upon longitudinal health within an individual's work setting.

\footnotetext{
1 Those indicating neither of these are denoted here as non-supervisors.

2 See the Appendix for sample construction notes.

${ }^{3}$ A later section attempts to deal with this issue.
} 
The BHPS contains several indicators of an individual's health. Here, we make use of three:

(i) subjective ill-health,

(ii) number of visits to the doctor,

(iii) mental strain.

We do so to allow a degree of corroboration of the regression results on any single health variable. These three variables are coded such that a higher value indicates worsening health. The paper therefore estimates ill-health ${ }^{4}$ regression equations (we use only cardinal methods but ordered estimators give the same results).

Subjective ill health is a self rating of one's health on a cardinal 5-point scale, where $5=$ very poor through to $1=$ excellent. The number of visits to the doctor -available in BHPS data as a grouped variable -- is another simple measure of how healthy an individual might be. The final dependent variable is that of psychological ill-health. It is captured here using a General Health Questionnaire (GHQ) measure of mental strain, on a 0 to 36 scale. The same variable -- defined more fully in the Appendix -- has been used in a large medical and psychiatric literature such as Cardozo et al (2000) and Pevalin and Ermisch (2004), and in health-economics research by, for example, Shields and Wheatley Price (2005) and Gardner and Oswald (2004). All three variables have positive skew; most individuals mark themselves in surveys as relatively healthy. Individuals' mean rating of their subjective ill-health is 2.02. They visit their doctor (ie, their General Practitioner, or GP, in British jargon) on average 1.77 times each year. This is on a numerical $0-10$ scale. They have mean mental strain of 10.76 on a 0 -36 scale. A simple correlation matrix is shown in Table

\footnotetext{
${ }^{4}$ A fuller description of the variables is given in the section Notes to Tables at the end of the paper.
} 
1. As might be expected, people who are less healthy on one criterion are more likely to be recorded as less healthy on the other two.

Health declines as people age. Simple within-promoted group comparisons are therefore not likely to be sufficient; we cannot merely measure the same individual's health across $\mathrm{T}-1$ to $\mathrm{T}+3$. This is illustrated in Table 2, which shows that subjective ill health, visits to the GP, and mental strain all deteriorate over a five-year period. Subjective ill-health worsens in Table 2 by 0.07 points; visits to the doctor by 0.10 points; mental health by 0.39 points. It is difficult to discern whether declining health across time here is due to extraneous factors, or, perhaps more plausibly, to the natural process of ageing. We attempt to overcome this by comparing particular individuals' health levels with those among a control group. The sample is separated into treatment and control groups -- those promoted at $\mathrm{T}$ and those never promoted -and comparisons made between them.

Our study examines three possible types of promotions: workers promoted from

(1) non-supervisor to supervisor,

(2) supervisor to manager and

(3) those going directly from non-supervisor to manager.

The final promotion type represents the largest gain in occupational status. Each promotion case has individuals' health contrasted to that of an appropriate control group, namely, individuals who remain as non-supervisors for promotion types 1 and 3 and supervisors for the $2^{\text {nd }}$ promotion category.

The comparison, in the data analysis, takes place across the entire 5-year period. 


\section{Results}

We begin by depicting the cross-sectional differences in health across levels of worker seniority. This is demonstrated, with gradual inclusion of a set of control variables, in Table 3.

Table 3's evidence reveals the positive association commonly seen in empirical studies of socio-economic status and health. The strongest correlation with occupational grade in the table is observed for subjective ill-health. Managers in column 1 of Table 3 report themselves 0.189 points healthier than non-supervisors; supervisors are 0.058 points healthier than non-supervisors. Here the occupational variables remain significant even when other socio-economic variables, such as income and education, are added to the regression equation. For the number-of-visitsto-the-GP variable, the evidence in Table 3 is not as clear. The coefficients, although beginning with some significance for managers, only border on the $10 \%$ level of significance once controls are added. Mental strain follows a similar, and slightly stronger, pattern. Managers have lower levels of mental strain and the coefficients are well defined.

In Table 3, smoking appears to have the negative consequences that might be expected. Ceteris paribus, women rate their own health worse. Moreover, they go to their doctor more often, and have higher mental strain. Income, unlike education, doesn't appear to offer an important explanation of an individual's health. Interestingly, the least-educated and the married individuals have significantly lower levels of mental strain. Concentrating on subjective health, we can evaluate the importance of a position of control in the workplace in light of other variables. The variable for being a manager, for instance, explains nearly as much of the association with health as smoking does and is associated with twice the benefit of being educated 
to degree level. Even once we control for the individual's access to resources and his or her education level, large benefits still remain.

Although confirming decades of previous evidence on the positive association between health and socio-economic status, Table 3 should not be viewed as proof of causality.

Table 4 (on promotion from non-supervisor to supervisor), Table 5 (on promotion from supervisor to manager) and Table 6 (on promotion from nonsupervisor to manager) move to longitudinal patterns. The first and third sets of promotions draw upon approximately 15,000 worker-year observations and up to 330 and 324 instances of promotion respectively; the second is based on approximately 1200 worker-year observations and up to 436 instances of promotion. These tables report both the raw means and the differences between groups -- both with and without controls ${ }^{5}$-- for subjective ill-health, visits to the doctor, and GHQ mental strain. The data run from $\mathrm{T}-1$ to $\mathrm{T}+3$. Occupational promotion occurs, by construction, at $\mathrm{T}^{6}$.

Consider the mean differences across the groups found in the second column from the end in each table. In Table 4, the mean reported ill-health of our two main groups -- those who will not and those who will later be promoted to the rank of supervisor -- is initially similar at 2.02 and 1.97. In the year of promotion, ill-health has fractionally improved, at 1.94, among the workers who do gain seniority. By three years later, the numbers for the two groups are, respectively, 2.09 and 2.04. Thus, contrary to the claims that promotion will bring improvements to health, both have worsened approximately equally; there is no relative improvement in health

\footnotetext{
5 The regressions with controls are available upon request.

${ }^{6}$ It is possible to start and end the analysis at different time points, but that greatly reduces the sample size without affecting our principal findings. The result of extending the analysis up until $\mathrm{T}+5$, for example, is shown in table 8.
} 
among the people who become supervisors. The Table 4 upper panel's bottom-right number of 0.01 , which measures the difference-in-difference, shows that not even Type II errors could explain the poor prediction of the promotion leading to better health hypothesis. For the visits-to-the-doctor variable in Table 4, those individuals who will go on to be promoted in $\mathrm{T}$ show up in the data set as significantly healthier in time $\mathrm{T}-1$ than the others. They have 1.56 visits per year compared to the 1.78 visits of the individuals who will not be promoted in T. By the end of the period, however, the $\mathrm{T}+3$ visits score is actually slightly worse among the promotees. The differencein-difference estimates even suggest that the health deterioration is much quicker for the promoted group using the number of doctor visits to indicate health. The only support, from Table 4, that promotion will result in better health is in the lower panel of the table, namely, in the data on GHQ mental strain scores. Here there is a little evidence that psychological health worsens faster among the non-promoted in the short term. At $\mathrm{T}$ the promoted group have significantly less mental strain than the non-promoted group, nevertheless, the improvement in mental strain is not large enough to have a significant influence on the difference-in-difference estimator. It will be seen later that even this disappears when regression controls are added.

Table 5 studies those who become managers after having been in a supervisory role. There is evidence from the means in the top panel of the table that the (future) promotees begin with better subjective health -- by 0.10 points -- than the others. However, although this health gap widens fractionally in certain years, there is no persistent improvement after the job promotion. By $\mathrm{T}+3$, the difference-indifference is only 0.02 and positive. Again, there seems no evidence that promotion will improve the individual's health. 
The only stark result on changes in health, in Table 5, is for Doctor Visits. This is the $-0.33^{\wedge}$ number on the change between $\mathrm{T}-1$ and $\mathrm{T}+1$. Hence, recently promoted managers go on to visit their doctor less often. The effect is large. As the mean of Visits is 1.7 , this estimate implies approximately a $20 \%$ fall in visits to the doctor after promotion to manager. Moreover, there is some consistency in this evidence for an improvement from time T. For the other time periods, the drop can be seen, in the right hand corner of the middle panel of Table 5, to be smaller at around -0.2 , which when compared to pre-promotion period T-1 corresponds to an approximately $10 \%$ decline in visits to the GP. This appears to be more encouraging for the claim that taking a promotion improves health (although a critic might potentially raise an alternative explanation, namely, that managers simply become short of time).

By contrast, on the GHQ mental strain measure in Table 5, if anything the promotees do worse by time $\mathrm{T}+3$. They begin in $\mathrm{T}-1$ with fractionally better mental health and end with slightly worse mental health. Although the null of zero cannot be rejected, the measured relative worsening is 0.32 points.

Table 6 again studies those who become managers. However, this case is particularly interesting because these people initially begin in a non-supervisory role. Hence the table provides information on 'large' promotions. This group of individuals, it might be said, are given the greatest boost to their status. Again there is evidence, although now much stronger, that the (future) promotees begin with much better health. Initial subjective and mental ill-health are both significantly better to begin with than among those not promoted. At $\mathrm{T}$, the promoted group even visit the doctor significantly fewer times. These health differences persist but do not significantly improve for the subjective ill-health variable up until T+3. 'Visits to the 
doctor' does show some significant improvement, much like the other promoted-tomanager group. Mental stress displays similar patterns to the other promoted-tomanager group and actually worsens. However, now the null of zero on this difference can be rejected. The promoted group begin with significantly better psychological health but by $\mathrm{T}+3$ they have the same mental strain levels as those not promoted. In fact they reach similar levels by $\mathrm{T}+1$ and the difference-in-difference estimates are positive and significantly different from zero.

This result, in the bottom right section of Table 6's lower panel, runs strongly counter to the hypothesis that promotion improves health: those who obtain the largest boost to status here seem to show the clearest deterioration in mental health.

The means of Tables 4, 5 and 6 imply that over a five-year interval, whilst appearing to suggest some differences in health across promoted and non-promoted groups, any longitudinal health improvements are insignificantly different from zero at the 5\% significance level. Both promoted-to-manager groups, however, do in the raw data show one significant sign of a health gain. Most of the nine panels of Tables 4, 5 and 6 suggest that putative promotees start out as healthier but that no further improvement to health comes after the gain in seniority.

Other factors are associated with health and promotion. The final columns in Tables 4, 5 and 6 show the differences between the groups once the time period, age, education, gender, marital status and smoking status at $\mathrm{T}$ are held constant ${ }^{7}$. Across the first two groups -- those promoted to supervisors and those promoted to managers from a supervisory role -- most significant differences have disappeared, or have not been accentuated. In the final group -- those promoted to manager from nonsupervisor -- there is still fairly strong evidence that it is the healthiest individuals

\footnotetext{
7 The controls match those used earlier in Table 3 but with income excluded. Some regressions, however, with an income control are contained at the end of the paper.
} 
who get promoted, but that the promotion does not appear to offer further benefits to their health. This seems discouraging for the proponents of the theory that high work status makes people healthy.

There is some slight evidence from Tables 5 and 6 that those promoted to the position of manager show a health improvement in the short term. Using the visits-tothe doctor indicator, both groups demonstrate signs of improvement. For those promoted from non-supervisors to supervisors the difference-in-difference estimator is only on the border of significance at conventional levels, and is not convincingly sustained through the long term to time period $\mathrm{T}+3$. For those promoted to managers from non-supervisors, a slower deterioration in health is significant at the $5 \%$ level up until $\mathrm{T}+3$. Perhaps importantly, a difference-in-difference estimator uncovers only slim evidence that promoted groups benefit from more slowly declining health, in either the short- or mid-term, when compared to others. In fact, mental health tends to deteriorate fastest among those who receive the largest status improvement.

A plausible conclusion from these results is that causality does not run from status to health. In part, it seems that the healthiest individuals may get promoted in at least one of the groups, but this result alone does not fully explain the social health gradient initially observed in Table 3 . There is a residual that needs to be explained. Arguably the cross-sectional association is driven by a third unobservable factor, such as behavioural or genetic factors. If there is a large benefit from being promoted, as potentially suggested by the Whitehall studies, then it is undetectable across our observed time frame. Good health, at least in the long term, apparently does not follow from job promotion. The decline in visits to the doctor of both promoted to manager groups in Tables 5 and 6 is the closest to evidence for the contrary. 


\section{Objections and Counters}

Our test is a simple one. It is sensible to consider objections.

There is much noise in the data. Hence (Concern \#1) we are conscious that our findings might in principle be explained by a Type II error. Moreover, promotion is non-random and there are potentially other ways in which the patterns in the data could be explained. These include the possibility that (Concern \#2) the promoted groups endured substantial health deterioration relative to the control group in the years leading up to the promotion, with promotion merely restoring it. Alternatively (Concern \#3) the individuals who really improve in health might somehow be missed from our sub-sample. This could occur if an individual promoted at $\mathrm{T}$ went on to then get demoted or promoted within the three years, or even left the work-force altogether.

We try to probe these possible explanations.

\section{Concern \#1}

A simple check on the possibility that our negative conclusions stem from Type II errors is to ignore the standard errors and focus on coefficient signs. In Tables 4, 5 and 6, looking at difference-in-differences in the bottom right corner of the panels, there are 24 out of 36 negatives when including controls and only 21 negatives without controls. A second check is to examine the sign on the longer-term effects with controls added in these Tables. This coefficient is negative in only 3 out of 9 instances both with and without controls. These splits do not support the hypothesis that promotion improves health.

Our data set necessarily aggregates across different kinds of work and different sectors. Therefore a further argument could be made against the occupational status variable. Whilst we expect the individual's answer to the status variable to have 
a large degree of internal consistency, there may be variation across industries. We test this possibility by carrying out the same analysis on individuals who work and remain in the manufacturing industry and again separately for the public sector. The results of this check are given in Table 7 . The treatment group declines substantially in size, which make it difficult to pick up significant differences. However, if again we leave aside the t-statistics and instead focus only on the coefficient signs for this relatively homogenous set of individuals, there are, consistently with the null of randomness, 11 instances out of 18 in which there is a negative value.

Those who get promoted to a supervisory position in the public sector become significantly less stressed. Evidence for this is found in spite of the small treatment group. A further look at those promoted to manager from the supervisor position shows a coefficient that, although insignificant, is of a similar magnitude. The difference-in-difference estimate of the large promotion group (non-supervisors to managers) also exhibits a positive coefficient. The sample sizes are very small but could be indicative of a protective health effect that is unique only to public sector workers. Combining all three promotion types increases the sample size, and the effect of any promotion in the public sector is also analysed in Table 7. It seems that those promoted in the public sector do experience some relative improvement in their mental strain by around 2.7 points. This improvement is large at around $25 \%$ of mean levels and significantly different from zero at conventional levels.

The improvement to mental strain found in the public sector is in contrast to our previous finding, in the whole sample, that mental stress significantly worsened across some promotion groups in the wider population. It could be that the public sector has special features that make it possible to gain health protection from 
improved work status. (The important work of Marmot and colleagues was on employees working in the civil service).

Table 8 extends the period of analysis and tests whether the promoted group have a slower deterioration in health up until $\mathrm{T}+5$. Table 8 further investigates whether those individuals who stay at the same address for the entire five year analysis -- T-1 to $\mathrm{T}+3$-- gain any benefits to their health. Since no firm-level indicators are available, use of the individual's address allows us to eliminate some of those individuals who may have moved firms. Neither test yields results supportive of the promotion-leads-to-health hypothesis.

\section{Concern \#2}

To deal with the second objection, it is necessary to determine whether, prior to promotion, (i) poor health or (ii) steadily deteriorating health somehow predicts promotion at T. Tables 4, 5 and 6 contradict (i), showing that healthier individuals get promoted; on (ii), probit estimation can be carried out across each promotion category, with deteriorating health (health measure at $\mathrm{T}-1$ minus $\mathrm{T}$ ) used as a predictor of promotion. Results are shown in Table 9 and we observe that the null of zero on the coefficients cannot be rejected. The positive coefficients imply, although mostly insignificantly different from zero, that individuals had a slower deterioration in health before promotion. This adds some weight to the argument that there is a $3^{\text {rd }}$ variable driving their promotion and health. Interestingly, women seem more likely to be promoted to a managerial position from a supervisory role but are less likely to figure in either of the other two groups. Education, as might be expected, is also a strong predictor of later promotion.

\section{Concern \#3}


The third objection is more difficult to overcome. Promoted individuals are lost from the sample on three accounts: they get further promoted or demoted within the three years; they leave the workforce; or they exit the BHPS completely. On this last point, little can be done. However, it is hard to see, intuitively, why the particularly healthy people should exhibit high attrition from the panel. The first two, however, can be tracked with comparisons against control and treatment groups.

Table 10 mirrors the estimation of health changes from $\mathrm{T}-1$ to $\mathrm{T}+3$ seen previously in Tables 4,5 and 6. A separate comparison is made for those who stay in employment, and those who leave the workforce. There is no evidence that those who subsequently change roles become healthier. The only clear outcomes arise for those who leave the workforce completely, but they show a worsening of health. Similar effects are found in the changes in health across other time periods. This appears to indicate that those omitted from our main analysis are not getting health benefits either; if anything, the promotees here seem to be getting less healthy through time.

Finally, Table 11 suggests that the inclusion of an income variable does not materially alter the coefficient in the Doctor Visits result for managers.

\section{Conclusion}

This paper is a longitudinal inquiry into the hypothesis that status makes people healthy. It draws upon data from a nationally representative sample of employees. We cannot find persuasive evidence that promotion improves a person's health. We conclude in the full sample that after being promoted the mental health of managers typically deteriorates, and in a way that goes beyond merely a short-term change. The paper's negative results do not appear to be the product of Type II errors. 
By exploiting an occupational-role question in the British Household Panel Survey, which gives an indication of a person's degree of workplace seniority, the paper first replicates the cross-section association between health and occupational status that is commonly found in previous writings. It then attempts to probe causality. The analysis does this by following individuals who undergo a promotion, and by trying to discern any health differences among them, when compared to a control group, before and after job promotion. Once other controls are included in the regression equation, few or no differences are observable across the two groups. A promotion to the role of supervisor, in particular, apparently does not increase a person's physical or mental health.

The exception to these broadly negative implications for the theory that improved occupational status brings health benefits is illustrated in our difference-indifference results in Table 5. Those promoted in time period $\mathrm{T}$ to the role of manager do alter in one way. From time T, they visit their doctor approximately $10 \%$ less frequently. On its own this finding should be treated with some caution. As observed in our Table 3, the visits-to-the-doctor variable has not only the lowest association with the occupational status variable but it may also be associated with the time available to care for one's health. The other main finding -- that managers become more stressed -- is perhaps supportive of this explanation.

In contrast to the interesting work of Sapolsky (2004), we therefore do not uncover evidence that status-to-health causality extends to humans. Such results are reminiscent of sceptical conclusions in Ruhm (2000) and Snyder and Evans (2006).

The paper's results should be treated cautiously. Our measures of health are imperfect; we can follow people for only a small number of years after they gain extra seniority; job promotion is not randomly assigned in the real world, and, although not 
confirmed by any of our paper's checks, might in principle be correlated in some unusual way ${ }^{8}$ with later alterations in general health status; it is possible that in period $\mathrm{T}-1$ there are individuals who correctly sense they will be promoted and have already, if only subconsciously, discounted that and thus gained a health boost prior to time period T's gain in status.

We are not sure how to reconcile these results with the more supportive ones that have been found, using data on Oscar and Nobel Prize winners and nominees, in the work of Redelmeier and Singh (2001) and Rablen and Oswald (2008). One conjecture might be that it takes a major change in status to make a difference to physical and mental health. Perhaps health does not respond in a linear dose-response way, but rather is a strongly convex function of status. Perhaps status works its effects over decades rather than years. Further longitudinal research will be needed before we have a deep understanding of the causes of the status-health correlation found in cross-section data.

\footnotetext{
${ }^{8}$ Here our negative findings have one interpretive advantage: the likely bias goes in the other direction. If promotion really improves people's health, then to make sense of our results using epidemiological theory it would be necessary to believe, arguably against common intuition, that individuals with a high probability of deteriorating health are the ones most likely to gain an increase in workplace seniority.
} 


\section{Appendix}

\section{Income's Inclusion in the Regression Equations}

Does inclusion of income change anything? In the main analysis, it was excluded, since an income rise is likely to accompany a promotion. The introduction of income, in Table 10, adds almost nothing to the effect of the promoted dummy.

\section{Sample Construction}

All three promoted groups are of interest in the analysis: those promoted from non-supervisor to both supervisor and manager, and those promoted from supervisor to manager. Individuals in employment and indicating their position at $\mathrm{T}$ were sourced from every wave of the BHPS. Each observation at $\mathrm{T}$ was tracked from $\mathrm{T}-1$ through to $\mathrm{T}+3$, and where available, the health measures taken. Occupational position changes were then analyzed and two groups, both control and treatment, created.

\section{Control Groups}

A control group of those not promoted is required. Those who maintained the same position (nonsupervisor or supervisor) for the full five years were a control group for the relevant promoted group.

\section{Treatment Groups}

Those who were initially in the control group at $\mathrm{T}-1$ but promoted at $\mathrm{T}$, and maintained this until at least $\mathrm{T}+3$, made up the treatment group. Inevitably, since requiring a full five years of data, waves 1 , 12, 13 and 14 could not be included. This makes an overall sample size of approximately 15,000 observations. It is a balanced panel: individuals give answers to the health question for each of the five years. Thus the sample size varies depending on the health variable under analysis.

Those promoted at $\mathrm{T}$ but who did not remain in the promoted position for all three years were separately coded -- depending on whether observed as still working, changing roles, or leaving work entirely. These groups are used in the analysis in Section 5.

By the nature of our sample construction, some individuals appear as multiple observations. This occurs in two circumstances. First, an individual may maintain a role for longer than 5 years. Second, a single individual may enter on a number of occasions if they experience a break in employment of which at least five years of employment exist either side. In both scenarios it is difficult to know which observation should be included as all spells contain valuable information. Both are kept as observations in the analysis.

\section{Definition of GHQ Mental Ill-health}

A GHQ score, defined to lie between zero and 36, is a psychiatric screening instrument that is as an amalgamation of answers to the questions: Have you recently:

1. Been able to concentrate on whatever you are doing?

2. Lost much sleep over worry?

3. Felt that you are playing a useful part in things?

4. Felt capable of making decisions about things?

5. Felt constantly under strain?

6. Felt you could not overcome your difficulties?

7. Been able to enjoy your normal day-to-day activities?

8. Been able to face up to your problems?

9. Been feeling unhappy and depressed?

10. Been losing confidence in yourself?

11. Been thinking of yourself as a worthless person?

12. Been feeling reasonably happy all things considered? 


\section{References}

Abbott, D. H., E. B. Keverne, F. B. Bercovitch, C. A. Shively, S. P. Medoza, W. Saltzman, C. T. Snowdon, T. E. Ziegler, M. Banjevic, T. Garland, and R. M. Sapolsky, 2003, "Are subordinates always stressed? A comparative analysis of rank differences in cortisol levels among primates," Hormones and Behavior 43, 67-82.

Abbott, D. H., W. Saltzman, N. J. Schultz-Darken, and P. L. Tannenbaum, 1998, "Adaptations to subordinate status in female marmoset monkeys," Comparative Biochemistry and Physiology C-Toxicology \& Pharmacology 119, 261-274.

Adams, P., M. D. Hurd, D. McFadden, A. Merrill, and T. Ribeiro, 2003, "Healthy, wealthy, and wise? Tests for direct causal paths between health and socioeconomic status," Journal of Econometrics 112, 3-56.

Adda, J., T. Chandola, and M. Marmot, 2003, "Commentary - socio-economic status and health: Causality and pathways," Journal of Econometrics 112, 57-63.

Ala-Mursula, L., J. Vahtera, A. Linna, J. Pentti, and M. Kivimaki, 2005, "Employee worktime control moderates the effects of job strain and effort-reward imbalance on sickness absence: The 10-town study," Journal of Epidemiology and Community Health 59, 851-857.

Anderson, M., and M. Marmot, 2007, The effects of social status on heart disease: Evidence from Whitehall, CUDARE Working Paper 1055.

Bosma, H., M. G. Marmot, H. Hemingway, A. C. Nicholson, E. Brunner, and S. A. Stansfeld, 1997, "Low job control and risk of coronary heart disease in Whitehall II (prospective cohort) study," British Medical Journal 314, 558-565.

Cantarero, D., and M. Pascual, 2005, "Socio-economic status and health: Evidence from the ECHP," Economics Bulletin 9, 17.

Cardozo, B. L., A. Vergara, F. Agani, and C. A. Gotway, 2000, "Mental health, social functioning, and attitudes of Kosovar Albanians following the war in Kosovo," JAMA-Journal of the American Medical Association 284, 569-577.

Cutler, D., A. Deaton, and A. Lleras-Muney, 2006, "The determinants of mortality," Journal of Economic Perspectives 20, 97-120.

Deaton, A., 2003, "Health, inequality, and economic development," Journal of Economic Literature 41, 113-158.

Duleep, H. O., 1986, "Measuring the effect of income on adult mortality using longitudinal administrative record data," Journal of Human Resources 21, 238-251.

Duncan, G. J., M. C. Daly, P. McDonough, and D. R. Williams, 2002, "Optimal indicators of socioeconomic status for health research," American Journal of Public Health 92, 1151-1157.

Ettner, S. L., 1996, "New evidence on the relationship between income and health," Journal of Health Economics 15, 67-85. 
Feldman, J. J., D. M. Makuc, J. C. Kleinman, and J. Cornonihuntley, 1989, "National trends in educational differentials in mortality," American Journal of Epidemiology 129, 919-933.

Fischer, J. A. V., and A. Sousa-Poza, Forthcoming 2009, "Does job satisfaction improve the health of workers? New evidence using panel data and objective measures of health," Health Economics 18, 71-89.

Frijters, P., J. Haisken-DeNew, and M. A. Shields, 2005, Socio-economic status, health shocks, life satisfaction and mortality: Evidence from an increasing mixed proportional hazard model, Centre for Economic Policy Research Discussion Paper.

Fuchs, V. R., 2004, "Reflections on the socio-economic. Correlates of health," Journal of Health Economics 23, 653-661.

Gardner, J., and A.J. Oswald, 2004, "How is mortality affected by money, marriage, and stress?," Journal of Health Economics 23, 1181-1207.

Griffin, J. M., R. Fuhrer, S. A. Stansfeld, and M. Marmot, 2002, "The importance of low control at work and home on depression and anxiety: Do these effects vary by gender and social class?," Social Science \& Medicine 54, 783-798.

Johnson, N. J., P. D. Sorlie, and E. Backlund, 1999, "The impact of specific occupation on mortality in the US National Longitudinal Mortality Study," Demography 36, 355-367.

Lahelma, E., and T. Valkonen, 1990, "Health and social inequities in Finland and elsewhere," Social Science \& Medicine 31, 257-265.

Lorgelly, P. K., and J. Lindley, 2008, "What is the relationship between income inequality and health? Evidence from the BHPS," Health Economics 17, 249-265.

Macleod, J., G. D. Smith, C. Metcalfe, and C. Hart, 2005, "Is subjective social status a more important determinant of health than objective social status? Evidence from a prospective observational study of Scottish men," Social Science \& Medicine 61, 1916-1929.

Marmot, M. G., 2004, Status syndrome: How your social standing directly affects your health and life expectancy, Bloomsbury Publishing PLC London.

Marmot, M. G., H. Bosma, H. Hemingway, E. Brunner, and S. Stansfeld, 1997, "Contribution of job control and other risk factors to social variations in coronary heart disease incidence," Lancet 350, 235-239.

Marmot, M. G., G. Rose, M. Shipley, and P. J. S. Hamilton, 1978, "Employment grade and coronary heart-disease in British civil-servants," Journal of Epidemiology and Community Health 32, 244-249.

Marmot, M. G., M. J. Shipley, and G. Rose, 1984, "Inequalities in death - specific explanations of a general pattern," Lancet 1, 1003-1006. 
Marmot, M. G., G. D. Smith, S. Stansfeld, C. Patel, F. North, J. Head, I. White, E. Brunner, and A. Feeney, 1991, "Health inequalities among British civil-servants - the Whitehall-II study," Lancet 337, 1387-1393.

McDonough, P., G. J. Duncan, D. Williams, and J. House, 1997, "Income dynamics and adult mortality in the United States, 1972 through 1989," American Journal of Public Health 87, 1476-1483.

Menchik, P. L., 1993, "Economic-status as a determinant of mortality among blackand-white older men - does poverty kill?," Population Studies-A Journal of Demography 47, 427-436.

Pevalin, D. J., and J. Ermisch, 2004, "Cohabiting unions, repartnering and mental health," Psychological Medicine 34, 1553-1559.

Rablen, M. D., and A. J. Oswald, 2008, "Mortality and immortality: The Nobel Prize as an experiment into the effect of status upon longevity," Journal of Health Economics 27, 1462-1471.

Redelmeier, D. A., and S. M. Singh, 2001, "Survival in academy award-winning actors and actresses," Annals of Internal Medicine 134, 955-962.

Ruhm, C. J., 2000, "Are recessions good for your health?," Quarterly Journal of Economics 115, 617-650.

Sapolsky, R. M., 2004, "Social status and health in humans and other animals," Annual Review of Anthropology 33, 393-418.

Sapolsky, R. M., L. M. Romero, and A. U. Munck, 2000, "How do glucocorticoids influence stress responses? Integrating permissive, suppressive, stimulatory, and preparative actions," Endocrine Reviews 21, 55-89.

Shields, M. A., and S. W. Price, 2005, "Exploring the economic and social determinants of psychological well-being and perceived social support in England," Journal of the Royal Statistical Society Series A-Statistics in Society 168, 513-537.

Smith, J. P., 1999, "Healthy bodies and thick wallets: The dual relation between health and economic status," Journal of Economic Perspectives 13, 145-166.

Snyder, S. E., and W. N. Evans, 2006, "The effect of income on mortality: Evidence from the social security notch," Review of Economics and Statistics 88, 482-495.

West, P., 1991, "Rethinking the health selection explanation for health inequalities," Social Science \& Medicine 32, 373-384.

Wilkinson, R., 1986, "Income and mortality," in R. Wilkinson, ed., Class and health: Research and longitudinal data, Tavistock, London.

—, 2001, Mind the gap: Hierarchies, health and human evolution, Yale University Press, New Haven. 
Wolfson, M., G. Rowe, J. F. Gentleman, and M. Tomiak, 1993, "Career earnings and death - a longitudinal analysis of older Canadian men," Journals of Gerontology 48, S167-S179. 


\section{Notes to Tables}

\section{Regressions include observations across all years separated by promoted to manager/supervisor groups where specified.}

\section{Description of Variables}

\begin{tabular}{|c|c|}
\hline Subjective Ill-health & $\begin{array}{l}\text { The individual's rating of their health status over the last twelve months, } \\
\text { where } 1 \text { =excellent, } 2 \text { =good, } 3=\text { fair, } 4=\text { poor, } 5=\text { very poor }\end{array}$ \\
\hline Visits to the doctor & $\begin{array}{l}\text { The number of visits to their General Practitioner in the past year. This } \\
\text { is a categorical variable. None, one or two, three to five, six to ten, or ten } \\
\text { plus are the available options. These are recoded to be the minimum } \\
\text { value in each category }(0,1,3,6 \text { and } 10) \text {. This is an underestimation, but } \\
\text { ensures consistency across categories and individuals. }\end{array}$ \\
\hline Mental strain & $\begin{array}{l}\text { This variable is a } 1 \text { to } 36 \text { scale of the level of mental strain obtained } \\
\text { from the General Health Questionnaire (GHQ). There are } 12 \text {, zero to } 3 \\
\text { point questions that include; among others, the individuals ability to } \\
\text { overcome problems, their decision capabilities, sleep, concentration and } \\
\text { general feelings of depression. }\end{array}$ \\
\hline Non-supervisor & $\begin{array}{l}\text { Individual's managerial duties are neither manager or supervisory, yet } \\
\text { they are still in employment }\end{array}$ \\
\hline Supervisor & Individual's managerial duties are that of a supervisor or foreman \\
\hline Manager & Individual's managerial duties are that of a manager \\
\hline Promoted at $\mathbf{T}$ & $\begin{array}{l}\text { Individuals promoted at } \mathrm{T} \text { (to supervisor or manager) and remained until } \\
\mathrm{T}+3\end{array}$ \\
\hline Promoted at $T$ but left workforce & $\begin{array}{l}\text { Individuals promoted at } \mathrm{T} \text { (to supervisor or manager) but did not remain } \\
\text { until } \mathrm{T}+3 \text { as they left the workforce at some point }\end{array}$ \\
\hline Promoted at $\mathrm{T}$ but subsequently changed role & $\begin{array}{l}\text { Individuals promoted at } \mathrm{T} \text { (to supervisor or manager) but did not remain } \\
\text { until } \mathrm{T}+3 \text { as they subsequently changed role through further promotion } \\
\text { or demotion }\end{array}$ \\
\hline Age & Individual's age \\
\hline Female & Individual is female (excluded dummy: male) \\
\hline Married & $\begin{array}{l}\text { Individual is married (excluded dummy: all non married individuals } \\
\text { including single, widow, divorced and separated) }\end{array}$ \\
\hline Smoker & Individual is a smoker (excluded dummy: all non-smoking individuals) \\
\hline Education level & $\begin{array}{l}\text { Specifies the individual's highest level of education obtained.(College } \\
\text { and Graduate dummies used with excluded dummy for those who either } \\
\text { left after high school or dropped out) }\end{array}$ \\
\hline Logarithm of income (at 2005 living costs) & $\begin{array}{l}\text { The logarithm of an individual's own annual income, with all years, } \\
\text { deflated to } 2005 \text { living costs }\end{array}$ \\
\hline
\end{tabular}


Table 1: Pearson Correlation Coefficients for the Three Ill-health Measures +

\begin{tabular}{|l|c|c|c|}
\hline & Subjective Ill Health & $\begin{array}{c}\text { Visits to the } \\
\text { Doctor }\end{array}$ & Mental Strain \\
\hline Subjective Ill-health & 1 & - & - \\
\hline Visits to the Doctor & $0.40(\mathrm{n}=16864)$ & 1 & - \\
\hline Mental Strain & $0.27(\mathrm{n}=15957)$ & $0.20(\mathrm{n}=15915)$ & 1 \\
\hline
\end{tabular}

+ all coefficients are statistically significantly different from zero at the 0.01 level 
Table 2: Ill-health Over Time within the Whole Sample

\begin{tabular}{|c|c|c|c|c|c|c|c|c|c|}
\hline \multicolumn{4}{|c|}{ Subjective Ill Health } & \multicolumn{3}{|c|}{ Visits to the Doctor } & \multicolumn{3}{|c|}{ Mental Strain (GHQ) } \\
\hline & $\mathbf{N}$ & Mean & $\begin{array}{l}\text { Standard } \\
\text { Deviation }\end{array}$ & $\mathbf{N}$ & Mean & $\begin{array}{l}\text { Standard } \\
\text { Deviation }\end{array}$ & $\mathbf{N}$ & Mean & $\begin{array}{c}\text { Standard } \\
\text { Deviation }\end{array}$ \\
\hline & 17724 & 2.0 & & 16 & 1.2 & & & 10 & 4.74 \\
\hline & 17724 & 2.02 & 0.80 & 16881 & 1.77 & 2.29 & 15974 & 10 & 4.77 \\
\hline+1 & 17724 & 2.04 & 0.81 & 168 & 1.81 & 2.34 & 15974 & 10.85 & 4.85 \\
\hline+2 & 17724 & 2.06 & 0.81 & 16881 & 1.84 & 2.37 & 15974 & 10.89 & 4.89 \\
\hline & 17724 & 2.08 & 0.82 & 16881 & 1.87 & 2.42 & 15974 & 11.02 & 4.95 \\
\hline
\end{tabular}


Table 3: Cross-section Regression Equations for Subjective Ill-health, Visits to the Doctor, and Mental Strain

Explanatory Variables

Manager

Supervisor

Year Dummies

Age

Age-squared

Female

Married

Smoker

Education Level

College

Graduate

Logarithm of Income (at 2005 living costs)

$\begin{array}{lcccc}\text { Constant } & 2.031 & 1.757 & 1.765 & 1.792 \\ & (315.03)^{* *} & (27.41)^{* *} & (27.23)^{* *} & (94.70)^{* *} \\ \text { Observations } & 17724 & 17724 & 17689 & 16881 \\ \text { R-squared } & 0.0026 & 0.04 & 0.04 & 0.006 \\ \text { Absolute value of t-statistics in parentheses; } * \text { significant at } 5 \% \text { level; ** significant at } 1 \% \text { level }\end{array}$

Absolute value of t-statistics in parentheses; * significant at $5 \%$ level; ** significant at $1 \%$ level

This is a full-sample regression that combines all promoted control and treatment group samples. Subsequent analysis separates these.

Visits to the Doctor
Dependent Variable:

\section{Mental Strain (GHQ)}

\begin{tabular}{|c|c|c|c|c|c|c|c|c|}
\hline $\begin{array}{c}-0.189 \\
(6.36)^{* * *}\end{array}$ & $\begin{array}{c}-0.168 \\
(5.72)^{* *}\end{array}$ & $\begin{array}{c}-0.147 \\
(4.93) * *\end{array}$ & $\begin{array}{c}-0.276 \\
(3.17) * *\end{array}$ & $\begin{array}{l}-0.135 \\
(1.58)\end{array}$ & $\begin{array}{l}-0.134 \\
(1.52)\end{array}$ & $\begin{array}{c}-0.746 \\
(4.02)^{* *}\end{array}$ & $\begin{array}{c}-0.652 \\
(3.55) * *\end{array}$ & $\begin{array}{c}-\mathbf{0 . 7 1 3} \\
(3.79) * *\end{array}$ \\
\hline-0.058 & -0.049 & $\mathbf{- 0 . 0 4 7}$ & -0.064 & 0.085 & 0.068 & -0.315 & -0.207 & -0.195 \\
\hline$(2.71)^{* *}$ & $(2.30)^{*}$ & (2.19)* & (1.02) & (1.37) & (1.08) & $(2.36) *$ & $(1.56)$ & (1.46) \\
\hline & Jointly & Jointly & & Jointly & Jointly & & Jointly & Jointly \\
\hline & Significant & Significant & & Significant & Significant & & Significant & Significant \\
\hline & 0.004 & 0.006 & & -0.053 & -0.057 & & 0.258 & 0.261 \\
\hline & (1.34) & $(1.80)$ & & $(5.46)^{* *}$ & $(5.56)^{* *}$ & & $(12.47)^{* *}$ & $(11.84)^{* *}$ \\
\hline & -0.000 & -0.000 & & 0.001 & 0.001 & & -0.003 & -0.003 \\
\hline & $(0.51)$ & (1.01) & & $(5.31)^{* *}$ & $(5.44)^{* *}$ & & $(11.75)^{* *}$ & $(11.17)^{* *}$ \\
\hline & 0.049 & 0.043 & & 0.903 & 0.933 & & 1.364 & 1.331 \\
\hline & $(4.05)^{* *}$ & $(3.46)^{* *}$ & & $(25.75)^{* *}$ & $(23.74)^{* *}$ & & $(18.12)^{* *}$ & $(15.77)^{* *}$ \\
\hline & -0.016 & -0.018 & & 0.043 & 0.043 & & -0.512 & -0.505 \\
\hline & (1.11) & (1.28) & & (1.05) & (1.06) & & $(5.80)^{* *}$ & $(5.71)^{* *}$ \\
\hline & 0.170 & 0.166 & & 0.075 & 0.071 & & 0.120 & 0.152 \\
\hline & $(12.67)^{* *}$ & $(12.27)^{* *}$ & & (1.92) & (1.78) & & (1.43) & (1.79) \\
\hline & & 0.000 & & & 0.061 & & & 0.108 \\
\hline & & $(0.00)$ & & & $(1.45)$ & & & (1.21) \\
\hline & & -0.072 & & & -0.126 & & & 0.418 \\
\hline & & $(3.20)^{* *}$ & & & (1.90) & & & $(2.98)^{* *}$ \\
\hline & & -0.006 & & & 0.021 & & & -0.033 \\
\hline & & (1.95) & & & (1.39) & & & (1.05) \\
\hline 2.031 & 1.757 & 1.765 & 1.792 & 2.244 & 2.072 & 10.817 & 5.094 & 5.265 \\
\hline$(315.03)^{* *}$ & $(27.41)^{* *}$ & $(27.23)^{* *}$ & $(94.70) * *$ & $(11.96)^{* *}$ & $(10.86)^{* *}$ & $(267.04)^{* *}$ & $(12.64)^{* *}$ & $(12.86)^{* *}$ \\
\hline 17724 & 17724 & 17689 & 16881 & 16881 & 16848 & 15974 & 15974 & 15943 \\
\hline 0.0026 & 0.04 & 0.04 & 0.006 & 0.04 & 0.04 & 0.0013 & 0.03 & 0.03 \\
\hline
\end{tabular}

9

(6)

$84)^{* *}$

$17)^{* *}$

77)**

.71)*

152

108

98)**

.05)

15943

03 
Table 4: Ill-health Among the Non-Promoted Non-Supervisors and those Promoted to Supervisor (at time T)

Subjective Ill Health Numbers subject to rounding ^ ^ significant at $10 \%$ level; * significant at $5 \%$ level; ** significant at $1 \%$ level

\begin{tabular}{|c|c|c|c|c|c|c|c|c|}
\hline \multirow[b]{2}{*}{ Time Period } & \multicolumn{3}{|c|}{ Non-Promoted Group } & \multicolumn{3}{|c|}{ Promoted Group } & \multirow[b]{2}{*}{$\begin{array}{c}\text { Difference in } \\
\text { Mean across } \\
\text { Groups }\end{array}$} & \multirow[b]{2}{*}{$\begin{array}{c}\text { Difference in Mean } \\
\text { across Groups } \\
\text { (with controls) }\end{array}$} \\
\hline & $\mathbf{N}$ & Mean & $\begin{array}{l}\text { Standard } \\
\text { Deviation }\end{array}$ & $\mathbf{N}$ & Mean & $\begin{array}{l}\text { Standard } \\
\text { Deviation }\end{array}$ & & \\
\hline T-1 & 15425 & 2.02 & 0.80 & 330 & 1.97 & 0.81 & -0.05 & -0.05 \\
\hline $\mathbf{T}$ & 15425 & 2.03 & 0.80 & 330 & 1.94 & 0.77 & $-0.09 *$ & $-0.08^{\wedge}$ \\
\hline $\mathbf{T}+\mathbf{1}$ & 15425 & 2.06 & 0.82 & 330 & 1.99 & 0.78 & -0.07 & -0.06 \\
\hline $\mathbf{T}+\mathbf{2}$ & 15425 & 2.07 & 0.81 & 330 & 2.08 & 0.81 & 0.01 & 0.02 \\
\hline $\mathbf{T}+\mathbf{3}$ & 15425 & 2.09 & 0.82 & 330 & 2.04 & 0.81 & -0.04 & -0.04 \\
\hline \multicolumn{9}{|c|}{ Change Over Time } \\
\hline (T)-(T-1) & 15425 & 0.01 & 0.82 & 330 & -0.03 & 0.86 & -0.04 & -0.03 \\
\hline$(\mathrm{T}+1)-(\mathrm{T}-1)$ & 15425 & 0.03 & 0.87 & 330 & 0.02 & 0.93 & -0.01 & -0.02 \\
\hline$(\mathbf{T}+2)-(\mathrm{T}-1)$ & 15425 & 0.04 & 0.89 & 330 & 0.11 & 0.96 & 0.07 & 0.07 \\
\hline$(\mathbf{T}+3)-(\mathrm{T}-1)$ & 15425 & 0.06 & 0.91 & 330 & 0.08 & 0.95 & 0.01 & 0.01 \\
\hline
\end{tabular}

Visits to the Doctor

\begin{tabular}{|c|c|c|c|c|c|c|c|c|}
\hline \multirow[b]{2}{*}{ Time Period } & \multicolumn{3}{|c|}{ Non-Promoted Group } & \multicolumn{3}{|c|}{ Promoted Group } & \multirow[b]{2}{*}{$\begin{array}{c}\text { Difference in } \\
\text { Mean across } \\
\text { Groups }\end{array}$} & \multirow[b]{2}{*}{$\begin{array}{c}\text { Difference in Mean } \\
\text { across Groups } \\
\text { (with controls) }\end{array}$} \\
\hline & $\mathbf{N}$ & Mean & $\begin{array}{l}\text { Standard } \\
\text { Deviation }\end{array}$ & $\mathbf{N}$ & Mean & $\begin{array}{l}\text { Standard } \\
\text { Deviation }\end{array}$ & & \\
\hline T-1 & 14687 & 1.78 & 2.27 & 314 & 1.56 & 1.82 & $-0.22^{\wedge}$ & -0.11 \\
\hline $\mathbf{T}$ & 14687 & 1.79 & 2.30 & 314 & 1.54 & 1.90 & $-0.25^{\wedge}$ & -0.14 \\
\hline $\mathbf{T}+\mathbf{1}$ & 14687 & 1.83 & 2.35 & 314 & 1.75 & 2.40 & -0.09 & 0.03 \\
\hline $\mathbf{T}+\mathbf{2}$ & 14687 & 1.85 & 2.37 & 314 & 1.89 & 2.30 & 0.04 & 0.17 \\
\hline $\mathbf{T}+\mathbf{3}$ & 14687 & 1.89 & 2.43 & 314 & 1.92 & 2.41 & 0.04 & 0.16 \\
\hline \multicolumn{9}{|c|}{ Change Over Time } \\
\hline$(\mathbf{T})-(\mathrm{T}-1)$ & 14687 & 0.01 & 2.31 & 314 & -0.02 & 1.89 & -0.03 & -0.03 \\
\hline$(T+1)-(T-1)$ & 14687 & 0.05 & 2.55 & 314 & 0.19 & 2.27 & $\mathbf{0 . 1 3}$ & 0.14 \\
\hline$(\mathbf{T}+2)-(\mathrm{T}-1)$ & 14687 & 0.07 & 2.60 & 314 & 0.33 & 2.51 & $0.26^{\wedge}$ & $0.28^{\wedge}$ \\
\hline$(T+3)-(T-1)$ & 14687 & 0.11 & 2.69 & 314 & 0.36 & 2.60 & $0.26^{\wedge}$ & $0.27^{\wedge}$ \\
\hline
\end{tabular}

Mental Strain (GHQ)

\begin{tabular}{|c|c|c|c|c|c|c|c|c|}
\hline \multirow[b]{2}{*}{ Time Period } & \multicolumn{3}{|c|}{ Non-Promoted Group } & \multicolumn{3}{|c|}{ Promoted Group } & \multirow[b]{2}{*}{$\begin{array}{l}\text { Difference in } \\
\text { Mean across } \\
\text { Groups } \\
\end{array}$} & \multirow[b]{2}{*}{$\begin{array}{c}\text { Difference in Mean } \\
\text { across Groups } \\
\text { (with controls) }\end{array}$} \\
\hline & $\mathbf{N}$ & Mean & $\begin{array}{l}\text { Standard } \\
\text { Deviation }\end{array}$ & $\mathbf{N}$ & Mean & $\begin{array}{l}\text { Standard } \\
\text { Deviation }\end{array}$ & & \\
\hline T-1 & 13874 & 10.68 & 4.76 & 296 & 10.40 & 4.60 & -0.28 & -0.04 \\
\hline $\mathbf{T}$ & 13874 & 10.82 & 4.83 & 296 & 10.21 & 4.52 & $-0.61 *$ & -0.38 \\
\hline $\mathbf{T}+\mathbf{1}$ & 13874 & 10.89 & 4.89 & 296 & 10.44 & 4.74 & -0.44 & -0.22 \\
\hline $\mathbf{T}+2$ & 13874 & 10.93 & 4.91 & 296 & 10.80 & 4.90 & -0.13 & -0.08 \\
\hline $\mathbf{T}+\mathbf{3}$ & 13874 & 11.04 & 4.96 & 296 & 10.56 & 4.82 & $-0.48^{\wedge}$ & -0.28 \\
\hline \multicolumn{9}{|c|}{ Change Over Time } \\
\hline$(\mathbf{T})-(\mathbf{T}-1)$ & 13874 & 0.14 & 4.96 & 296 & -0.19 & 4.74 & -0.33 & -0.34 \\
\hline$(\mathrm{T}+1)-(\mathrm{T}-1)$ & 13874 & 0.21 & 5.22 & 296 & 0.05 & 4.80 & -0.16 & -0.19 \\
\hline$(\mathrm{T}+2)-(\mathrm{T}-1)$ & 13874 & 0.25 & 5.43 & 296 & 0.40 & 5.77 & 0.15 & 0.10 \\
\hline$(\mathrm{T}+3)-(\mathrm{T}-1)$ & 13874 & 0.36 & 5.55 & 296 & 0.16 & 5.45 & -0.20 & -0.26 \\
\hline
\end{tabular}


Table 5: Ill-health Among the Non-Promoted Supervisors and those Promoted to Manager (at time T)

Subjective Ill Health Numbers subject to rounding ^ $\wedge$ significant at $10 \%$ level; * significant at $5 \%$ level; ** significant at $1 \%$ level

\begin{tabular}{|c|c|c|c|c|c|c|c|c|}
\hline \multirow[b]{2}{*}{ Time Period } & \multicolumn{3}{|c|}{ Non-Promoted Group } & \multicolumn{3}{|c|}{ Promoted Group } & \multirow[b]{2}{*}{$\begin{array}{c}\text { Difference in } \\
\text { Mean across } \\
\text { Groups }\end{array}$} & \multirow[b]{2}{*}{$\begin{array}{c}\text { Difference in Mean } \\
\text { across Groups } \\
\text { (with controls) }\end{array}$} \\
\hline & $\mathbf{N}$ & Mean & $\begin{array}{l}\text { Standard } \\
\text { Deviation }\end{array}$ & $\mathbf{N}$ & Mean & $\begin{array}{l}\text { Standard } \\
\text { Deviation }\end{array}$ & & \\
\hline T-1 & 1209 & 1.98 & 0.81 & 436 & 1.88 & 0.83 & $-0.10 *$ & $-0.08^{\wedge}$ \\
\hline $\mathbf{T}$ & 1209 & 1.98 & 0.82 & 436 & 1.88 & 0.79 & $-0.10 *$ & $-0.08^{\wedge}$ \\
\hline $\mathbf{T}+\mathbf{1}$ & 1209 & 2.03 & 0.82 & 436 & 1.86 & 0.75 & $-0.17 * *$ & $-0.13 * *$ \\
\hline $\mathbf{T}+2$ & 1209 & 2.04 & 0.80 & 436 & 1.94 & 0.80 & $-0.10^{*}$ & $-0.09^{\wedge}$ \\
\hline $\mathbf{T}+\mathbf{3}$ & 1209 & 2.05 & 0.81 & 436 & 1.97 & 0.79 & $-0.09^{\wedge}$ & -0.05 \\
\hline \multicolumn{9}{|c|}{ Change Over Time } \\
\hline$(T)-(T-1)$ & 1209 & 0.00 & 0.79 & 436 & 0.00 & 0.82 & 0.00 & -0.00 \\
\hline$(\mathrm{T}+1)-(\mathrm{T}-1)$ & 1209 & 0.04 & 0.85 & 436 & -0.02 & 0.86 & -0.06 & -0.05 \\
\hline$(\mathbf{T}+2)-(\mathrm{T}-1)$ & 1209 & 0.06 & 0.85 & 436 & 0.06 & 0.89 & 0.00 & -0.01 \\
\hline$(\mathbf{T}+3)-(\mathrm{T}-1)$ & 1209 & 0.07 & 0.86 & 436 & 0.08 & 0.92 & 0.02 & 0.02 \\
\hline
\end{tabular}

Visits to the Doctor

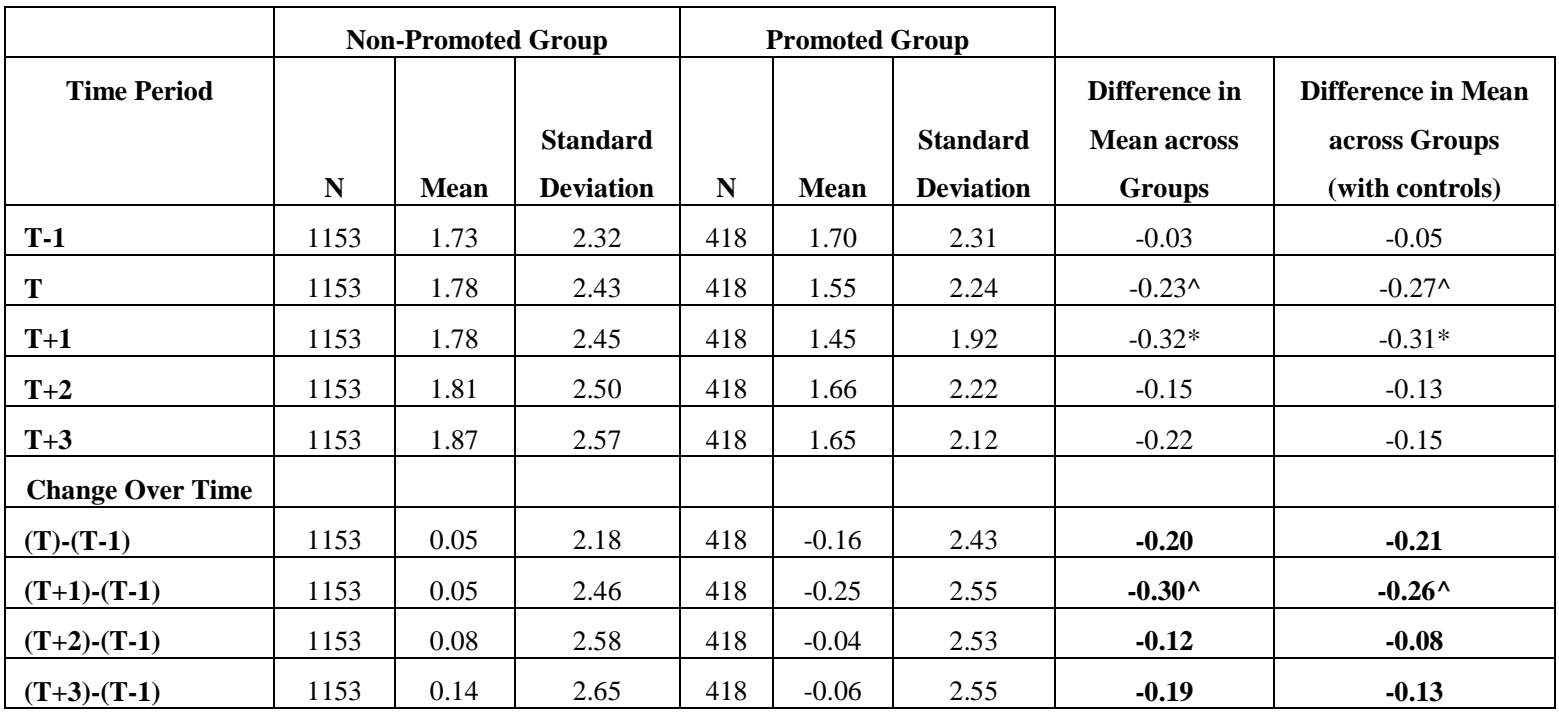

Mental Strain (GHQ)

\begin{tabular}{|c|c|c|c|c|c|c|c|c|}
\hline \multirow[b]{2}{*}{ Time Period } & \multicolumn{3}{|c|}{ Non-Promoted Group } & \multicolumn{3}{|c|}{ Promoted Group } & \multirow[b]{2}{*}{$\begin{array}{c}\text { Difference in } \\
\text { Mean across } \\
\text { Groups } \\
\end{array}$} & \multirow[b]{2}{*}{$\begin{array}{c}\text { Difference in Mean } \\
\text { across Groups } \\
\text { (with controls) }\end{array}$} \\
\hline & $\mathbf{N}$ & Mean & $\begin{array}{l}\text { Standard } \\
\text { Deviation }\end{array}$ & $\mathbf{N}$ & Mean & $\begin{array}{l}\text { Standard } \\
\text { Deviation }\end{array}$ & & \\
\hline T-1 & 1112 & 10.42 & 4.23 & 395 & 10.31 & 4.74 & -0.10 & -0.13 \\
\hline $\mathbf{T}$ & 1112 & 10.58 & 4.34 & 395 & 10.23 & 4.22 & -0.35 & -0.33 \\
\hline $\mathbf{T}+\mathbf{1}$ & 1112 & 10.53 & 4.44 & 395 & 10.76 & 4.58 & 0.23 & 0.18 \\
\hline $\mathbf{T}+2$ & 1112 & 10.60 & 4.56 & 395 & 10.56 & 4.81 & -0.04 & -0.19 \\
\hline $\mathbf{T}+\mathbf{3}$ & 1112 & 10.86 & 4.77 & 395 & 11.08 & 5.15 & 0.22 & 0.21 \\
\hline \multicolumn{9}{|c|}{ Change Over Time } \\
\hline$(T)-(T-1)$ & 1112 & 0.16 & 4.34 & 395 & -0.09 & 5.26 & -0.25 & -0.19 \\
\hline$(\mathrm{T}+1)-(\mathrm{T}-1)$ & 1112 & 0.11 & 4.61 & 395 & 0.45 & 5.37 & 0.34 & 0.31 \\
\hline$(\mathbf{T}+2)-(\mathrm{T}-1)$ & 1112 & 0.18 & 4.70 & 395 & 0.24 & 5.63 & 0.06 & -0.08 \\
\hline$(T+3)-(T-1)$ & 1112 & 0.44 & 5.05 & 395 & 0.76 & 5.90 & 0.32 & 0.34 \\
\hline
\end{tabular}


Table 6: Ill-health Among the Non-Promoted Non-supervisors and those Promoted to Manager (at time T)

Subjective Ill Health Numbers subject to rounding $\wedge$ significant at $10 \%$ level; * significant at $5 \%$ level; ** significant at $1 \%$ level

\begin{tabular}{|c|c|c|c|c|c|c|c|c|}
\hline \multirow[b]{2}{*}{ Time Period } & \multicolumn{3}{|c|}{ Non-Promoted Group } & \multicolumn{3}{|c|}{ Promoted Group } & \multirow[b]{2}{*}{$\begin{array}{c}\text { Difference in } \\
\text { Mean across } \\
\text { Groups } \\
\end{array}$} & \multirow[b]{2}{*}{$\begin{array}{c}\text { Difference in Mean } \\
\text { across Groups } \\
\text { (with controls) }\end{array}$} \\
\hline & $\mathbf{N}$ & Mean & $\begin{array}{l}\text { Standard } \\
\text { Deviation }\end{array}$ & $\mathbf{N}$ & Mean & $\begin{array}{l}\text { Standard } \\
\text { Deviation }\end{array}$ & & \\
\hline T-1 & 15425 & 2.02 & 0.80 & 324 & 1.86 & 0.81 & $-0.16^{* *}$ & $-0.13^{* *}$ \\
\hline $\mathbf{T}$ & 15425 & 2.03 & 0.80 & 324 & 1.79 & 0.74 & $-0.24 * *$ & $-0.19 * *$ \\
\hline $\mathbf{T}+\mathbf{1}$ & 15425 & 2.06 & 0.82 & 324 & 1.84 & 0.72 & $-0.22 * *$ & $-0.17 * *$ \\
\hline $\mathbf{T}+\mathbf{2}$ & 15425 & 2.07 & 0.81 & 324 & 1.88 & 0.80 & $-0.19 * *$ & $-0.15^{* *}$ \\
\hline $\mathbf{T}+\mathbf{3}$ & 15425 & 2.09 & 0.82 & 324 & 1.89 & 0.77 & $-0.20 * *$ & $-0.15^{* *}$ \\
\hline \multicolumn{9}{|c|}{ Change Over Time } \\
\hline$(T)-(T-1)$ & 15425 & 0.01 & 0.82 & 324 & -0.07 & 0.83 & $-0.08^{\wedge}$ & -0.06 \\
\hline$(\mathrm{T}+1)-(\mathrm{T}-1)$ & 15425 & 0.03 & 0.87 & 324 & -0.02 & 0.85 & -0.06 & -0.04 \\
\hline$(\mathrm{T}+2)-(\mathrm{T}-1)$ & 15425 & 0.04 & 0.89 & 324 & 0.01 & 0.87 & -0.03 & -0.03 \\
\hline$(\mathrm{T}+3)-(\mathrm{T}-1)$ & 15425 & 0.06 & 0.91 & 324 & 0.02 & 0.88 & -0.04 & -0.03 \\
\hline
\end{tabular}

Visits to the Doctor

\begin{tabular}{|c|c|c|c|c|c|c|c|c|}
\hline \multirow[b]{2}{*}{ Time Period } & \multicolumn{3}{|c|}{ Non-Promoted Group } & \multicolumn{3}{|c|}{ Promoted Group } & \multirow[b]{2}{*}{$\begin{array}{c}\text { Difference in } \\
\text { Mean across } \\
\text { Groups } \\
\end{array}$} & \multirow[b]{2}{*}{$\begin{array}{c}\text { Difference in Mean } \\
\text { across Groups } \\
\text { (with controls) }\end{array}$} \\
\hline & $\mathbf{N}$ & Mean & $\begin{array}{l}\text { Standard } \\
\text { Deviation }\end{array}$ & $\mathbf{N}$ & Mean & $\begin{array}{l}\text { Standard } \\
\text { Deviation }\end{array}$ & & \\
\hline T-1 & 14687 & 1.78 & 2.27 & 309 & 1.69 & 2.24 & -0.09 & 0.10 \\
\hline $\mathbf{T}$ & 14687 & 1.79 & 2.30 & 309 & 1.47 & 1.78 & $-0.32 *$ & -0.15 \\
\hline $\mathbf{T}+\mathbf{1}$ & 14687 & 1.83 & 2.35 & 309 & 1.39 & 1.64 & $-0.45^{* *}$ & $-0.25^{\wedge}$ \\
\hline $\mathbf{T}+2$ & 14687 & 1.85 & 2.37 & 309 & 1.51 & 2.03 & $-0.34 *$ & -0.13 \\
\hline $\mathbf{T}+\mathbf{3}$ & 14687 & 1.89 & 2.43 & 309 & 1.46 & 1.98 & $-0.43 * *$ & -0.21 \\
\hline \multicolumn{9}{|c|}{ Change Over Time } \\
\hline$(\mathrm{T})-(\mathrm{T}-1)$ & 14687 & 0.01 & 2.31 & 309 & -0.22 & 2.07 & $-0.23^{\wedge}$ & $-0.25^{\wedge}$ \\
\hline$(\mathrm{T}+1)-(\mathrm{T}-1)$ & 14687 & 0.05 & 2.55 & 309 & -0.30 & 2.30 & $-0.35^{*}$ & $-0.36 *$ \\
\hline$(\mathrm{T}+2)-(\mathrm{T}-1)$ & 14687 & 0.07 & 2.60 & 309 & -0.18 & 2.46 & -0.25 & -0.23 \\
\hline$(\mathrm{T}+3)-(\mathrm{T}-1)$ & 14687 & 0.11 & 2.69 & 309 & -0.23 & 2.53 & $-0.34 *$ & $-0.32 *$ \\
\hline
\end{tabular}

Mental Strain (GHQ)

\begin{tabular}{|c|c|c|c|c|c|c|c|c|}
\hline \multirow[b]{2}{*}{ Time Period } & \multicolumn{3}{|c|}{ Non-Promoted Group } & \multicolumn{3}{|c|}{ Promoted Group } & \multirow[b]{2}{*}{$\begin{array}{l}\text { Difference in } \\
\text { Mean across } \\
\text { Groups }\end{array}$} & \multirow[b]{2}{*}{$\begin{array}{l}\text { Difference in Mean } \\
\text { across Groups } \\
\text { (with controls) }\end{array}$} \\
\hline & $\mathbf{N}$ & Mean & $\begin{array}{l}\text { Standard } \\
\text { Deviation }\end{array}$ & $\mathbf{N}$ & Mean & $\begin{array}{l}\text { Standard } \\
\text { Deviation }\end{array}$ & & \\
\hline T-1 & 13874 & 10.68 & 4.76 & 297 & 10.00 & 5.42 & $-0.68 *$ & $-0.55^{*}$ \\
\hline $\mathbf{T}$ & 13874 & 10.82 & 4.83 & 297 & 9.86 & 4.66 & $-0.96 * *$ & $-0.85 * *$ \\
\hline $\mathbf{T}+\mathbf{1}$ & 13874 & 10.89 & 4.89 & 297 & 10.58 & 4.89 & -0.31 & -0.19 \\
\hline $\mathbf{T}+2$ & 13874 & 10.93 & 4.91 & 297 & 10.99 & 5.47 & 0.06 & 0.16 \\
\hline $\mathbf{T}+\mathbf{3}$ & 13874 & 11.04 & 4.96 & 297 & 11.15 & 5.25 & 0.12 & 0.20 \\
\hline \multicolumn{9}{|c|}{ Change Over Time } \\
\hline$(\mathrm{T})-(\mathrm{T}-1)$ & 13874 & 0.14 & 4.96 & 297 & -0.13 & 5.45 & -0.28 & -0.32 \\
\hline$(\mathrm{T}+1)-(\mathrm{T}-1)$ & 13874 & 0.21 & 5.22 & 297 & 0.58 & 5.93 & 0.37 & 0.34 \\
\hline$(\mathbf{T}+2)-(\mathbf{T}-1)$ & 13874 & 0.25 & 5.43 & 297 & 0.99 & 6.14 & $0.74 *$ & $0.66 *$ \\
\hline$(\mathrm{T}+3)-(\mathrm{T}-1)$ & 13874 & 0.36 & 5.55 & 297 & 1.16 & 6.79 & 0.80* & $0.70 *$ \\
\hline
\end{tabular}


Table 7: Difference-in-Difference ((T+3)-(T-1)) Estimates (with controls) for Individuals Working in the Public Sector and in Manufacturing Industry

\begin{tabular}{|c|c|c|c|}
\hline Promoted Group & Health Measure & $\begin{array}{l}\text { Public Sector (\# in } \\
\text { treatment/control) }\end{array}$ & $\begin{array}{c}\text { Manufacturing } \\
\text { Industry (\# in } \\
\text { treatment/control) }\end{array}$ \\
\hline \multirow{3}{*}{$\begin{array}{l}\text { Promoted to } \\
\text { Supervisor }\end{array}$} & Subjective Ill-Health & $0.01(8 / 420)$ & $0.08(67 / 2200)$ \\
\hline & Visits to the Doctor & $-0.33(8 / 409)$ & $0.28(65 / 2092)$ \\
\hline & Mental Strain & $-4.45 *(8 / 398)$ & $-0.72(62 / 1974)$ \\
\hline \multirow{3}{*}{$\begin{array}{l}\text { Promoted to Manager } \\
\text { (from supervisor) }\end{array}$} & Subjective Ill-Health & $-0.04(14 / 33)$ & $-0.22(37 / 244)$ \\
\hline & Visits to the Doctor & $0.05(13 / 32)$ & $-0.35(37 / 232)$ \\
\hline & Mental Strain & $-4.26(12 / 32)$ & $-0.04(35 / 223)$ \\
\hline \multirow{3}{*}{$\begin{array}{l}\text { Promoted to Manager } \\
\text { (from non-supervisor) }\end{array}$} & Subjective Ill-Health & $0.64^{\wedge}(8 / 420)$ & $-0.20(29 / 2200)$ \\
\hline & Visits to the Doctor & $0.21(7 / 409)$ & $-0.47(29 / 2092)$ \\
\hline & Mental Strain & $-0.48(7 / 398)$ & $0.97(29 / 1974)$ \\
\hline \multirow[t]{3}{*}{ Any Promotion } & Subjective Ill-Health & $0.12(30 / 453)$ & \\
\hline & Visits to the Doctor & $-0.27(28 / 441)$ & \\
\hline & Mental Strain & $-2.73 *(27 / 430)$ & \\
\hline
\end{tabular}

$\wedge$ significant at $10 \%$ level; $*$ significant at $5 \%$ level; ** significant at $1 \%$ level

As an aid to reading this table, the top left number of 0.01 (8/420) means that in the public sector a promotion to supervisor increases subjective illhealth by 0.01 points, and there are 8 people in this category, with 420 in the control category. 
Table 8: Difference-in-difference estimates for individuals that stay at the same address across all 5 years $((T+3)-(T-1))$ and those that stay in the promoted position up until $T+5((T+5)-(T-1))$

\begin{tabular}{|c|c|c|c|}
\hline Promoted Group & Health Measure & $\begin{array}{c}\text { Stay at the same } \\
\text { address across all } 5 \\
\text { years }((T+3)-(T-1))\end{array}$ & $\begin{array}{c}\text { Remain in promoted } \\
\text { position until } \mathbf{T}+5 \\
((\mathbf{T}+5)-(\mathbf{T}-1))\end{array}$ \\
\hline \multirow{3}{*}{$\begin{array}{l}\text { Promoted to } \\
\text { Supervisor }\end{array}$} & Subjective Ill-Health & $0.04(175 / 9377)$ & $0.01(122 / 7965)$ \\
\hline & Visits to the Doctor & $0.39^{\wedge}(175 / 9349)$ & $0.25(117 / 7607)$ \\
\hline & Mental Strain & $-0.28(164 / 8762)$ & $0.38(109 / 7181)$ \\
\hline \multirow{3}{*}{$\begin{array}{l}\text { Promoted to Manager } \\
\text { (from supervisor) }\end{array}$} & Subjective Ill-Health & $-0.07(233 / 779)$ & $-0.13^{\wedge}(229 / 469)$ \\
\hline & Visits to the Doctor & $-0.09(234 / 774)$ & $-0.20(220 / 456)$ \\
\hline & Mental Strain & $0.29(220 / 744)$ & $-0.52(206 / 451)$ \\
\hline \multirow{3}{*}{$\begin{array}{l}\text { Promoted to Manager } \\
\text { (from non-supervisor) }\end{array}$} & Subjective Ill-Health & $0.01(149 / 9377)$ & $-0.02(151 / 7965)$ \\
\hline & Visits to the Doctor & $-0.61(149 / 9349)$ & $-0.29(143 / 7607)$ \\
\hline & Mental Strain & $0.63(143 / 8762)$ & $-0.01(136 / 7181)$ \\
\hline
\end{tabular}


Table 9: Probit Equations using Change in Health from T-1 to T as a Predictor of Promotion

123

Dependent Variable:

Promotion to Supervisor at $T$

Subjective Ill

Health

Mental Strain

Visits to the

GP

4

5

Promotion to Manager at $\mathbf{T}$ (from Supervisor)

Explanatory Variables

at $T$

\section{Health change from}

T-1 to $\mathbf{T}$

\subsection{3}

$(0.84)$

0.003
$(0.24)$

\subsection{6}

$-0.007$

(2.94)**

$-0.215$

$-0.006$

(1.19)

$$
\begin{aligned}
& \text { 0.013 } \\
& (0.30)
\end{aligned}
$$

0.024
$(1.52)$

$-0.006$

$-0.012$

$-0.012$

(3.34)**

0.154

$-0.217$

(2.19)*

$(4.57)^{* *}$

(4.47)**

$-0.118$

$\begin{array}{lll}0.028 & 0.016 & 0.025 \\ (0.53) & (0.29) & (0.45)\end{array}$

0.037

(0.29)

(0.45)

$(0.45)$
0.047

Smoker

(0.71)

(0.73)

$(0.87)$

$$
\text { (1.52) }
$$

0.064

(0.77)

0.297

$(3.90)^{* *}$

0.096

College

0.099
$(1.89)$

0.067

(0.79)

(1.57)

$(1.57)$
0.063

Graduate

$$
-1.738
$$$$
\text { (0.72) }
$$

0.009
$(0.10)$

1.291
$(11.43)^{* *}$

$-1.762$

$(19.95)^{* *}$

$-1.745$

$(19.04)^{* *}$

$-0.420$

$(2.63)^{* *}$

14170

0.01

1645

0.01

0.01

0.09

Absolute value of t-statistics in parentheses; * significant at $5 \%$ level; ** significant at $1 \%$ level
Visits to the

GP Mental Strain
7

8

Promotion to Manager at T (from Non-Supervisor)

Subjective Ill Visits to the

Health GP

Mental Strain

$\begin{array}{ccccc}-0.014 & -0.013 & -0.003 & -0.004 & -0.003 \\ (3.72)^{* *} & (3.49)^{* *} & (1.39) & (1.56) & (1.34) \\ 0.148 & 0.139 & -0.263 & -0.257 & -0.257 \\ (2.05)^{*} & (1.89) & (5.39)^{* *} & (5.14) * * & (5.05)^{* *} \\ & & & & \\ -0.108 & -0.108 & 0.164 & 0.173 & 0.162 \\ (1.36) & (1.32) & (2.91)^{* *} & (3.00)^{* *} & (2.75)^{* *} \\ 0.092 & 0.107 & -0.027 & -0.004 & 0.005 \\ (1.09) & (1.24) & (0.46) & (0.07) & (0.08) \\ & & & & \\ 0.304 & 0.288 & 0.369 & 0.376 & 0.354 \\ (3.90)^{* *} & (3.62)^{* *} & (6.40)^{* *} & (6.34)^{* *} & (5.86)^{* *} \\ 1.312 & 1.333 & 0.992 & 1.009 & 0.979 \\ (11.33)^{* *} & (11.22)^{* *} & (15.84)^{* *} & (15.69) * * & (14.96)^{* *} \\ & & & & -2.161 \\ -0.369 & -0.398 & -2.162 & -2.166 & (20.45)^{* *} \\ (2.25)^{*} & (2.37)^{*} & (21.50)^{* *} & (20.84)^{* *} & 14171 \\ 1571 & 1507 & 15749 & 14996 & 0.09 \\ 0.09 & 0.09 & 0.09 & 0.10 & \end{array}$


Table 10: Regressions Showing Health Differences across Promoted Groups, and those who Subsequently Left the Workforce or Changed Role

\begin{tabular}{|c|c|c|c|c|c|c|c|c|c|}
\hline \multirow{3}{*}{ Dependent Variable: } & 1 & 2 & 3 & 4 & 5 & 6 & 7 & 8 & 9 \\
\hline & \multicolumn{3}{|c|}{ Promoted to Supervisor at $T$} & \multicolumn{3}{|c|}{ Promoted to Manager at $\mathbf{T}$ (from Supervisor) } & \multicolumn{3}{|c|}{ Promoted to Manager at $\mathrm{T}$ (from Manager) } \\
\hline & $\begin{array}{l}\text { Subjective Ill } \\
\text { Health }\end{array}$ & $\begin{array}{l}\text { Visits to the } \\
\text { GP }\end{array}$ & Mental Strain & $\begin{array}{c}\text { Subjective Ill } \\
\text { Health }\end{array}$ & $\begin{array}{l}\text { Visits to the } \\
\text { GP }\end{array}$ & Mental Strain & $\begin{array}{c}\text { Subjective Ill } \\
\text { Health }\end{array}$ & Visits to the GP & Mental Strain \\
\hline \multicolumn{10}{|l|}{$\begin{array}{l}\text { Explanatory Variables } \\
\text { at } T\end{array}$} \\
\hline \multirow{2}{*}{ Promoted at $\mathbf{T}$} & 0.014 & 0.277 & -0.242 & 0.015 & -0.144 & 0.336 & -0.044 & -0.298 & 0.716 \\
\hline & $(0.28)$ & (1.77) & $(0.74)$ & $(0.28)$ & $(0.91)$ & (1.01) & $(0.86)$ & (1.91) & $(2.16)^{*}$ \\
\hline \multirow{2}{*}{$\begin{array}{l}\text { Promoted at } \mathrm{T} \text { but left } \\
\text { workforce }\end{array}$} & 0.065 & 0.321 & 0.124 & -0.060 & 0.108 & 0.341 & 0.049 & 0.425 & 0.079 \\
\hline & (1.37) & $(2.20)^{*}$ & $(0.40)$ & $(\mathbf{0 . 8 4})$ & (0.49) & $(0.75)$ & $(0.72)$ & $(1.99)^{*}$ & (0.17) \\
\hline \multirow{2}{*}{$\begin{array}{l}\text { Promoted at } \mathrm{T} \text { but } \\
\text { subsequently changed } \\
\text { role }\end{array}$} & 0.010 & -0.032 & 0.284 & 0.009 & -0.115 & -0.417 & -0.051 & -0.148 & 0.176 \\
\hline & $(\mathbf{0 . 4 2})$ & $(0.46)$ & (1.92) & $(\mathbf{0 . 2 0})$ & $(\mathbf{0 . 8 6})$ & $(\mathbf{1 . 5 0 )}$ & $(\mathbf{1 . 3 4})$ & $(1.26)$ & $(0.70)$ \\
\hline \multirow[t]{2}{*}{ Age } & 0.001 & 0.008 & -0.026 & 0.002 & 0.005 & -0.014 & 0.001 & 0.007 & -0.028 \\
\hline & $(1.98)^{*}$ & $(4.06)^{* *}$ & $(6.28)^{* *}$ & $(1.16)$ & $(0.84)$ & $(1.25)$ & $(1.70)$ & $(3.63)^{* *}$ & $(6.34)^{* *}$ \\
\hline \multirow[t]{2}{*}{ Female } & -0.006 & 0.024 & -0.029 & 0.033 & 0.138 & -0.080 & -0.002 & 0.028 & -0.063 \\
\hline & $(0.45)$ & $(0.57)$ & $(0.32)$ & $(0.92)$ & $(1.25)$ & $(0.35)$ & $(0.17)$ & $(0.65)$ & $(0.68)$ \\
\hline \multirow[t]{2}{*}{ Married } & 0.021 & -0.086 & 0.442 & -0.005 & -0.000 & 0.172 & 0.032 & -0.069 & 0.444 \\
\hline & $(1.36)$ & $(1.81)$ & $(4.40)^{* *}$ & $(0.12)$ & $(0.00)$ & $(0.67)$ & $(2.01)^{*}$ & $(1.42)$ & $(4.23)^{* *}$ \\
\hline \multirow[t]{2}{*}{ Smoker } & 0.004 & 0.081 & -0.129 & 0.147 & 0.391 & 0.005 & 0.008 & 0.058 & -0.020 \\
\hline & $(0.24)$ & (1.71) & $(1.29)$ & $(3.45)^{* *}$ & $(3.00)^{* *}$ & $(0.02)$ & $(0.48)$ & (1.19) & $(0.19)$ \\
\hline \multicolumn{10}{|l|}{ Education Level } \\
\hline \multirow[t]{2}{*}{ College } & 0.002 & -0.054 & -0.014 & 0.046 & -0.073 & 0.238 & 0.015 & -0.024 & 0.022 \\
\hline & $(0.10)$ & $(1.06)$ & $(0.13)$ & (1.13) & $(0.59)$ & $(0.93)$ & $(0.90)$ & $(0.46)$ & $(0.20)$ \\
\hline \multirow[t]{2}{*}{ Graduate } & -0.029 & -0.029 & 0.051 & 0.032 & -0.140 & -0.227 & 0.002 & -0.045 & 0.043 \\
\hline & $(1.13)$ & $(0.37)$ & $(0.32)$ & $(0.58)$ & $(0.81)$ & $(0.64)$ & $(0.09)$ & $(0.58)$ & $(0.26)$ \\
\hline \multirow[t]{2}{*}{ Constant } & 0.006 & -0.175 & 1.157 & -0.081 & -0.178 & 0.868 & -0.004 & -0.159 & 1.188 \\
\hline & $(0.23)$ & $(2.09)^{*}$ & $(6.60)^{* *}$ & $(0.95)$ & $(0.68)$ & $(1.61)$ & $(0.13)$ & $(1.86)$ & $(6.49)^{* *}$ \\
\hline Observations & 17936 & 17065 & 16127 & 2572 & 2448 & 2358 & 16530 & 15713 & 14857 \\
\hline Pseudo R-squared & 0.0008 & 0.0019 & 0.0033 & 0.0058 & 0.0069 & 0.0042 & 0.0009 & 0.0018 & 0.0035 \\
\hline
\end{tabular}

Absolute value of t-statistics in parentheses; * significant at $5 \%$ level; ** significant at $1 \%$ level

All regressions match those found in Tables 6 through 11 (Column 9) except with the extra individuals who did not maintain their promotions. 
Table 11: Regressions Showing Health Differences with Income's Inclusion for the Promoted-to-Manager from Non-Supervisor Control and Treatment groups

Subjective IIl

Health at $\mathbf{T}$
2

Subjective Ill

Dependent

Variable:

Explanatory

Variables at $T$

Promoted Group

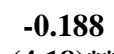

$-0.157$

(1.19)

$-0.892$

$(3.13)^{* * *}$

$-0.030$

(0.58)

0.069

$-0.002$

(0.43)

0.002

$(2.67)^{* *}$

$-0.006$

(0.40)

$(3.00)^{* *}$

0.907

$(5.07)^{* * *}$

1.527

$(17.12)^{* *}$

0.048

$-0.196$

(2.13)*

0.203

(2.23)*

$(12.47)^{* *}$

$(2.27)^{*}$

$$
0.003
$$

$-0.069$

$(2.89)^{* *}$

0.073

(1.62)

$-0.154$

$(2.19)^{*}$

1.844
$53.37)^{* *}$

1.370

$(11.83)^{* *}$

$\begin{array}{cc}15715 & 14964 \\ 0.04 & 0.04\end{array}$

0.192

$(1.96)^{*}$

0.489

$(3.23)^{* * *}$

8.875

$(35.05)^{* *}$

14141

0.03
0.027

(1.65)

0.010

(0.63)

0.034

(1.91)

0.025

(0.93)

0.039

(1.01)

15715

0.04
Observations

0.04
5

Visits to GP at Mental Strain

$T$ Difference at $T$ Difference

(T+3)-(T-1)

$(\mathbf{T}+3)-(\mathrm{T}-1)$

Absolute value of t-statistics in parentheses; * significant at $5 \%$ level; ** significant at $1 \%$ level 